\title{
Phenotyping of chronic obstructive pulmonary disease using the modified Bhalla scoring system for high-resolution computed tomography
}

\author{
Baykal Tulek MD ${ }^{1}$, Ali Sami Kivrak MD², Seda Ozbek MD², Fikret Kanat MD ${ }^{1}$, Mecit Suerdem MD ${ }^{1}$
}

\begin{abstract}
B Tulek, AS Kivrak, S Ozbek, F Kanat, M Suerdem. Phenotyping of chronic obstructive pulmonary disease using the modified Bhalla scoring system for high-resolution computed tomography. Can Respir J 2013;20(2):91-96.
\end{abstract}

BACKGROUND: Identifying different phenotypes of chronic obstructive pulmonary disease (COPD) is important for both therapeutic options and clinical outcome of the disease.

OBJECTIVE: To characterize the phenotypes of COPD according to high-resolution computed tomography (HRCT) findings; and to correlate HRCT scores obtained using the modified Bhalla scoring system with clinical and physiological indicators of systemic inflammation.

METHODS: The present study included 80 consecutive patients with stable COPD. HRCT scans were evaluated by two independent radiologists according to the modified Bhalla scoring system.

RESULTS: Fifty-four patients exhibited morphological changes on HRCT examination while 26 had no pathological findings. Patients with HRCT findings had lower spirometric measurements and higher levels of inflammation, and reported more exacerbations in the previous year compared with patients with no findings on HRCT. Patients with morphological changes were classified into one of three groups according to their HRCT phenotype(s): emphysema (E) only, E + bronchiectasis (B)/peribronchial thickening (PBT) or B/PBT only. Forced vital capacity (FVC), forced expiratory volume in $1 \mathrm{~s}\left(\mathrm{FEV}_{1}\right), \mathrm{FEV}_{1} / \mathrm{FVC}$ ratio, C-reactive protein (CRP) levels and the number of exacerbations among the groups were significantly different. Pairwise comparisons between the E only and E+B/PBT groups showed significantly lower $\mathrm{FVC}, \mathrm{FEV}_{1}$ and $\mathrm{FEV}_{1} / \mathrm{FVC}$ values, and higher CRP levels and number of exacerbations compared with the B/PBT group. No significant differences were found between the $\mathrm{E}+\mathrm{B} / \mathrm{PBT}$ and the $\mathrm{B} / \mathrm{PBT}$ groups. An inverse correlation was found between the total HRCT score and $\mathrm{FVC}, \mathrm{FEV}_{1}$ and $\mathrm{FEV}_{1} / \mathrm{FVC}$; the correlation was positive with $\mathrm{CRP}$ level, erythrocyte sedimentation rate and number of exacerbations.

CONCLUSION: The present study exposed the intimate relationship between phenotype(s) characterized by HRCT and scoring for morphological abnormalities; and clinical and functional parameters and inflammatory markers. The inclusion of HRCT among routine examinations for COPD may provide significant benefits both in the management and prognosis of COPD patients.

Key Words: Chronic obstructive pulmonary disease; High-resolution computed tomography; Phenotype

Chronic obstructive pulmonary disease (COPD) is a chronic inflammatory disease of the airways and lung parenchyma that leads to substantial morbidity and mortality, and affects approximately $10 \%$ of the population $>40$ years of age $(1-3)$. COPD is highly heterogeneous with regard to clinical presentation, response to treatment, limitation of lung function and survival expectancy. Defining a condition so heterogeneous exclusively by a patient's forced expiratory volume in $1 \mathrm{~s}\left(\mathrm{FEV}_{1}\right)$ may not always be adequate. The characterization of different phenotypes of COPD to better prognosticate mortality and exacerbation frequency has, therefore, increasingly attracted interest in recent years (4).

High-resolution computed tomography (HRCT) is currently the preferred imaging method in the diagnosis of diseases such as
La détermination du phénotype de la maladie pulmonaire obstructive chronique au moyen de l'indice de Bhalla modifié pour la tomodensitométrie à haute résolution

HISTORIQUE : Il est important de déterminer les divers phénotypes de la maladie pulmonaire obstructive chronique (MPOC), à la fois pour sélectionner des possibilités thérapeutiques et pour évaluer l'issue clinique.

OBJECTIF : Caractériser les phénotypes de la MPOC d'après la tomodensitométrie à haute résolution (TDHR) et corréler les indices de TDHR obtenus au moyen de l'indice de Bhalla modifié par des indicateurs cliniques et physiologiques de l'inflammation systémique.

MÉTHODOLOGIE : La présente étude incluait 80 patients consécutifs ayant une MPOC stable. Deux radiologistes indépendants ont évalué la TDHR conformément à l'indice de Bhalla modifié.

RÉSULTATS : Cinquante-quatre patients ont présenté des changements morphologiques à la TDHR, tandis que 26 n'avaient pas de problème pathologique. Les patients ayant des résultats à la TDHR présentaient des mesures spirométriques plus faibles, un taux d'inflammation plus élevé et un plus grand nombre d'exacerbations déclarées au cours de l'année précédente que ceux qui n'avaient pas de problèmes à la TDHR. Les chercheurs ont classé les patients présentant des changements morphologiques en trois groupes d'après leurs phénotypes à la TDHR : emphysème (E) seulement, E + bronchiectasie (B)/épaississement péribronchique (ÉPB) ou B/ÉPB seulement. La capacité vitale forcée (CVF), le volume expiratoire maximal par seconde (VEMS), le ratio entre le VEMS et la CVF, les taux de protéine C-réactive (CRP) et le nombre d'exacerbations différaient de manière significative entre les groupes. Les comparaisons par paire entre le groupe d'E seulement et le groupe d'E+B/ÉPB ont révélé des valeurs de CVF et de VEMS ainsi qu'un ratio entre la VEMS et la CVF considérablement plus faibles, de même que des taux de CRP et un nombre d'exacerbations plus élevés que dans le groupe de B/ÉPB. Les chercheurs n'ont constaté aucune différence significative entre le groupe $\mathrm{E}+\mathrm{B} / \mathrm{E} \mathrm{PB}$ et le groupe $\mathrm{B} / \mathrm{E} \mathrm{PB}$. Ils ont constaté une corrélation négative entre l'indice de TDHR total et la CVF, le VEMS et le ratio entre le VEMS et la CVF. Pour ce qui est du taux de CRP et de sédimentation érythrocytaire et du nombre d'exacerbations, la corrélation était positive.

CONCLUSION : La présente étude a exposé l'étroite relation entre les phénotypes caractérisés par une TDHR et un indice d'anomalies morphologiques ainsi qu'entre des paramètres cliniques et fonctionnels et des marqueurs inflammatoires. L'inclusion de la TDHR parmi les examens systématiques de la MPOC pourrait comporter d'importants avantages, tant pour la prise en charge que pour le pronostic des patients ayant une MPOC.

bronchiectasis (B) and emphysema (E), which cause morphological changes in the lungs (5). Its usefulness in the differential diagnosis of obstructive lung diseases has been established. The incidental finding of $\mathrm{B}$ and $\mathrm{E}$ has increased with the use of HRCT. Studies involving COPD patients also show that morphological phenotypes characterized with the help of HRCT may play an important role in the prognosis and management of the disease $(6,7)$.

The Bhalla scoring system (8), widely used particularly in pediatric or adult cystic fibrosis patients, is a method demonstrated to correlate with clinical and physiological characteristics $(9,10)$. To date, we are not aware of studies involving COPD patients correlating the Bhalla scoring system with clinical and physiological parameters of inflammation. The objective of the present study was to characterize the

${ }^{1}$ Department of Chest Diseases; ${ }^{2}$ Department of Radiology, Selcuk University Faculty of Medicine, Selcuklu, Konya, Turkey

Correspondence: Dr Baykal Tulek, Selcuk Universitesi Tip Fakultesi, Gogus Hastaliklari AD, Selcuklu, Konya, Turkey.

Telephone 90-532-7878327, fax 90-332-241-6065, e-mail baykaltulek@yahoo.com 


\section{TABLE 1}

\section{Modified Bhalla scoring system}

\begin{tabular}{|c|c|c|c|c|}
\hline \multirow[b]{2}{*}{ HRCT findings } & \multicolumn{4}{|c|}{ Score } \\
\hline & 0 & 1 & 2 & 3 \\
\hline Severity of bronchiectasis & Absent & Lumen slightly greater than adjacent vessel & Lumen $2 \times$ to $3 \times$ adjacent vessel & Lumen $>3 \times$ adjacent vessel \\
\hline Peribronchial thickening & Absent & Airwall thickness equal to adjacent vessel & $\begin{array}{c}\text { Airwall thickening } \leq 2 \times \text { adjacent } \\
\text { vessel }\end{array}$ & $\begin{array}{c}\text { Airwall thickening }>2 \times \\
\text { adjacent vessel }\end{array}$ \\
\hline Extent of bronchiectasis (BPS) & Absent & $1-5$ & $6-9$ & $>9$ \\
\hline Extent of mucous plugging (BPS) & Absent & $1-5$ & $6-9$ & $>9$ \\
\hline Sacculation/abscesses (BPS) & Absent & $1-5$ & $6-9$ & $>9$ \\
\hline Generation of bronchial divisions & Absent & Up to fourth generation & Up to fifth generation & Up to sixth generation \\
\hline Bullae, n & Absent & Unilateral & Bilateral & $>4$ \\
\hline Emphysema (BPS) & Absent & $1-5$ & $>5$ & \\
\hline Collapse/consolidation & Absent & Subsegmental & Segmental/lobar & \\
\hline Mosaic perfusion* & Absent & $1-5$ & $>5$ & \\
\hline
\end{tabular}

*Modification to the Bhalla scoring system. BPS Bronchopulmonary segments; HRCT High-resolution computed tomography

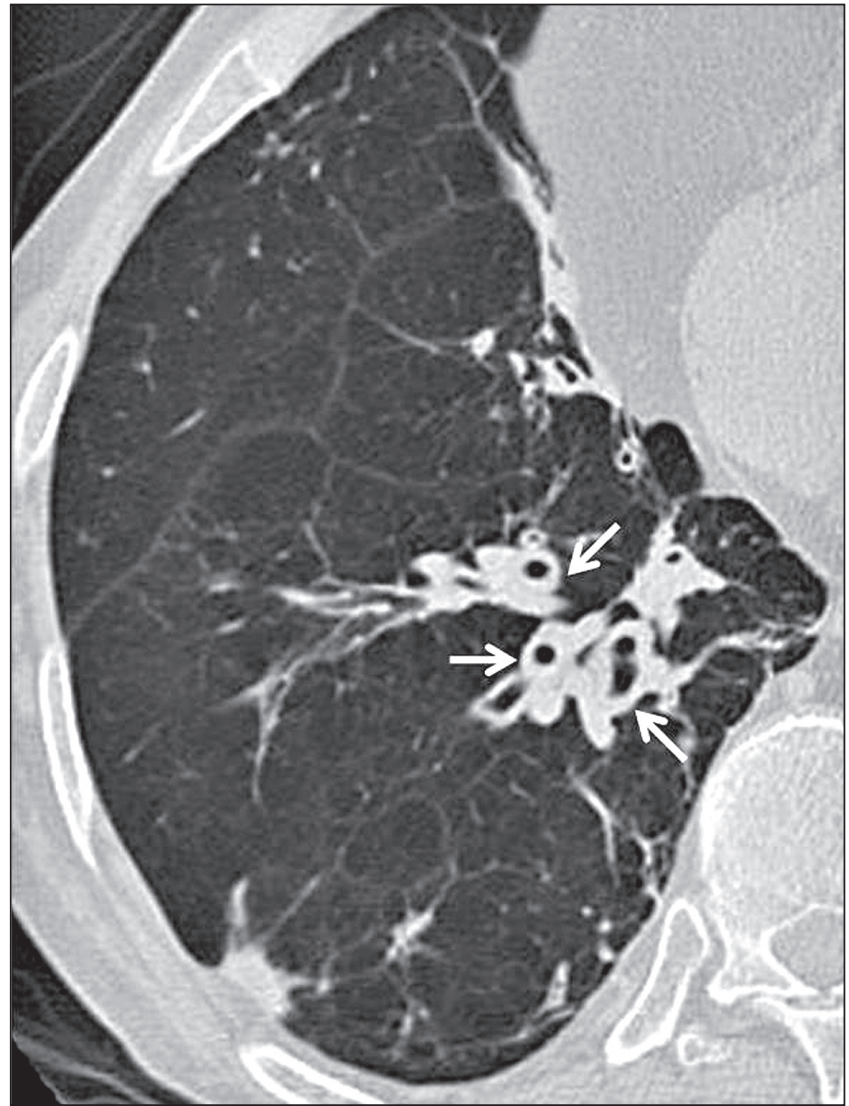

Figure 1) High-resolution computed tomography image of the right lower lung lobe showing bronchiectasis with severe bronchial wall thickening (arrows)

phenotypes of COPD according to HRCT findings, and to assess the correlation of HRCT scores with clinical and physiological indicators of systemic inflammation.

\section{Patients}

\section{METHODS}

The present study included 80 patients seen at the outpatient clinics of the Chest Diseases Department of Selcuk University, Konya, Turkey, between January 2010 and May 2012. COPD was diagnosed according to internationally recognized guidelines using clinical history, symptoms and a postbronchodilator forced expiratory volume in $1 \mathrm{~s}$ $\left(\mathrm{FEV}_{1}\right) /$ forced vital capacity $(\mathrm{FVC})$ ratio $<0.70$. The patients' disease status was classified by their predictive $\mathrm{FEV}_{1}$ values as being mild $\left(\mathrm{FEV}_{1}\right.$ $\geq 80 \%)$, moderate $\left(50 \% \leq \mathrm{FEV}_{1}<80 \%\right)$, severe $\left(30 \% \leq \mathrm{FEV}_{1}<50 \%\right)$ and very severe $\left(\mathrm{FEV}_{1}<30 \%\right)(11)$.
All patients were in a stable phase of disease at the time of HRCT imaging and none had experienced an exacerbation within the previous six weeks. Medical records of all patients were reviewed and detailed histories of the patients were obtained. Patients with a previous diagnosis of $B$ or those with clinical evidence of B were not eligible for the study. In addition, patients with sinobronchitis or diffuse panbronchiolitis, asthma, interstitial or inflammatory lung disease, sequelae of tuberculosis, history of cerebrovascular incidents, heart disease or severe esophageal reflux were also excluded from the study. The patients' smoking history, start date of COPD-related complaints, daily expectoration volume and the number of acute attacks in the year preceding HRCT imaging were also recorded from the patients' charts. Results of respiratory function tests performed in the stable phase, C-reactive protein and total albumin levels, and erythrocyte sedimentation rate (ESR) within the period from one before to one month after HRCT imaging were also recorded.

HRCT imaging without contrast medium was performed using a fourdetector computed tomography (CT) scanner (Aquilon 4, Toshiba, Japan). Sequential scanning from the pulmonary apex to the diaphragm at $10 \mathrm{~mm}$ intervals with $1 \mathrm{~mm}$ collimation was performed at maximal inspiration on supine patients. Other details of image acquisition were as follows: voltage $120 \mathrm{kVp}$, effective tube current $150 \mathrm{mAs}$, detector collimation $1 \mathrm{~mm} \times 4$, acquisition time $1 \mathrm{~ms}$; a bone algorithm and a $512 \times 512$ matrix were used for image reconstruction. The lung windows had a width of 1600 Houndsfield units and a level of -600 .

All of the examination results were evaluated retrospectively according to the modified Bhalla scoring system by two independent radiologists (ASK and SD) who were unaware of the patients clinical condition. The scores attributed by ASK and SD were compared to calculate interobserver agreement. The scoring system proposed by Bhalla et al (8) for CT scans evaluates the degree and extent of B, mucus plug formation and peribronchial thickening (PBT), and the number of bronchial divisions that are involved. Abscesses, sacculations, bullae, E, areas of collapse and consolidation are also recorded. This scoring system was modified by the addition of an evaluation of mosaic perfusion, and a total score was obtained by adding the scores for each class of abnormality; total scores could range from 0 to 27 (Table 1). Radiological findings were reported according to established, published guidelines. Definitions for the findings were as follows: B - internal diameter of a bronchus larger than that of its companion pulmonary artery with the bronchial lumen failing to taper over $\geq 2 \mathrm{~cm}$ and visualization of bronchi $<1 \mathrm{~cm}$ from the costal pleura (Figures 1 and 2); PBT - thickness of the bronchial wall $>1 \mathrm{~mm}$ (Figures 1 and 2); mucus plugging - image of plugs in large bronchi or peripheral tree-in-bud sign; sacculation - cystic appearance of bronchi; bulla - round air space of $>1 \mathrm{~cm}$ diameter with a thin wall; $\mathrm{E}$ - decreased attenuation, disorganization of the vascular structure, absence of recognizable walls (Figure 2); consolidation - intensified opacification of the lung hiding the parenchymal pattern; and mosaic perfusion - hyperlucent, hypovascular zone. 


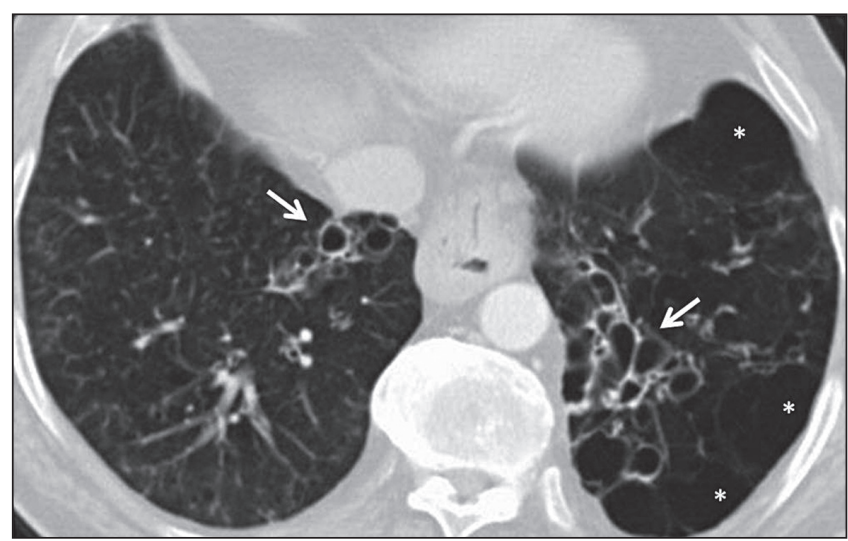

Figure 2) High-resolution computed tomography image of the lower lobes demonstrating bilateral cystic bronchiectasis with bronchial wall thickening (arrows). Predominantly left-sided subpleural distribution of emphysematous spaces are noted $(*)$

Patients with morphological changes were classified into one of three groups according to their HRCT phenotype(s): E only; E+B/PBT; and $\mathrm{B} / \mathrm{PBT}$ only. In defining these phenotypes, a cut-off Bhalla score $\geq 1$ for any finding was used for each group.

\section{Statistics}

For continuous variables, the descriptive summary parameters were the mean and SD; categorical variables were tabulated as absolute counts and percentages. Variables were tested for normality of distribution using the Kolmogorov-Smirnov test. Clinical findings and spirometry and blood values of the phenotype groups were tested for differences using the Kruskal-Wallis test. Paired comparisons using the MannWhitney $U$ test were performed in the presence of a significant result of the overall comparisons. A Bonferroni correction was applied in the case of multiple comparisons. Spearman's rank correlation ( $r$ ) was used to investigate correlations between HRCT scores and other variables. Interobserver agreement for scoring was tested and, for each observation, the alpha coefficient for agreement was calculated and expressed with its $95 \%$ confidence limits. The level of statistical significance was set at an alpha value of $5 \%$ for type I error.

\section{RESULTS}

The mean $( \pm$ SD) age of the 80 COPD patients was $68 \pm 8$ years; $76(96 \%)$ of these patients were male. All stages of COPD were represented, although a majority exhibited moderate $(46.3 \%)$ and severe $(30 \%)$ disease. Spirometry studies were available for all patients, while CRP level had been obtained in 74, ESR in 71 and total albumin level in 61. All subjects were in the 'current smoker' category (ie, currently smoking or stopped smoking less than one year previously). Patient and disease characteristics are summarized in Table 2.

HRCT evaluations diagnosed E in 47 (58.8\%) patients, B in 27 (33\%) and PBT in $25(31.3 \%)$. Patients were classified into one of three groups according to HRCT phenotype(s) (ie, E only, E+B/PBT and B/PBT only [the overlap between B and PBT was substantial; hence, the evaluation of B and PBT as a single group]) (Figure 3).

When grouping the patients according to the presence or absence of HRCT findings, no significant differences were found with regard to age, sex, smoking status, COPD duration and albumin level; spirometric measurements were worse in those with HRCT findings, who also had significantly higher CRP and ESR values (Table 3 ).

On comparing the three phenotypes described as E only, E+B/PBT and $\mathrm{B} / \mathrm{PBT}$ only, the differences in $\mathrm{FVC}, \mathrm{FEV}_{1}, \mathrm{FEV}_{1} / \mathrm{FVC}$ ratio, CRP level and the number of exacerbations were found to be significant (Table 4). Pairwise comparison using the Mann-Whitney U test between the $\mathrm{E}$ only and $\mathrm{E}+\mathrm{B} / \mathrm{PBT}$ groups showed significantly lower $\mathrm{FVC}, \mathrm{FEV}_{1}$ and $\mathrm{FEV}_{1} / \mathrm{FVC}$ ratio, and higher CRP level and number of exacerbations compared with the $\mathrm{B} / \mathrm{PBT}$ only group. Comparison

\section{TABLE 2}

\section{Demographic and clinical characteristics}

\begin{tabular}{|c|c|}
\hline Parameter & \\
\hline Age, years & $68 \pm 8$ \\
\hline Male sex, n (\%) & $76(95)$ \\
\hline Smoking, pack-years & $33.5 \pm 14.4$ \\
\hline Onset of symptoms, years & $11.6 \pm 6.4$ \\
\hline \multicolumn{2}{|l|}{ COPD severity, n (\%) } \\
\hline Mild & $14(17.5)$ \\
\hline Moderate & $37(46.3)$ \\
\hline Severe & $24(30)$ \\
\hline Very severe & $5(6.3)$ \\
\hline Exacerbations, previous year & $1.6 \pm 1.6$ \\
\hline \multicolumn{2}{|l|}{ Sputum amount, $\mathrm{mL}, \mathrm{n}(\%)$} \\
\hline$<5$ & $34(42.5)$ \\
\hline $5-25$ & $29(36.3)$ \\
\hline$>25$ & $17(21.3)$ \\
\hline \multicolumn{2}{|l|}{ Usual sputum character, n (\%) } \\
\hline Mucoid & $66(82.5)$ \\
\hline Mucopurulent & $9(11.3)$ \\
\hline Purulent & $5(6.3)$ \\
\hline Total HRCT score, median (min-max) & $2(0-17)$ \\
\hline FVC, \% predicted & $79.7 \pm 16.7$ \\
\hline $\mathrm{FEV}_{1}, \%$ predicted & $57.1 \pm 19.4$ \\
\hline $\mathrm{FEV}_{1} / \mathrm{FVC}$ & $56.3 \pm 11.4$ \\
\hline C-reactive protein $(\mathrm{n}=74), \mathrm{mg} / \mathrm{L}$ & $7.6 \pm 6.6$ \\
\hline Erythrocyte sedimentaion rate $(n=71), \mathrm{mm} / \mathrm{h}$ & $24.7 \pm 17.4$ \\
\hline Albumin, $g / L(n=61)$ & $39 \pm 4.0$ \\
\hline
\end{tabular}

Data presented as mean \pm SD unless otherwise indicated. COPD Chronic obstructive pulmonary disease; HRCT High-resolution computed tomograhy; FEV 1 Forced expiratory volume in 1 s; FVC Forced vital capacity; max Maximum; min MInimum

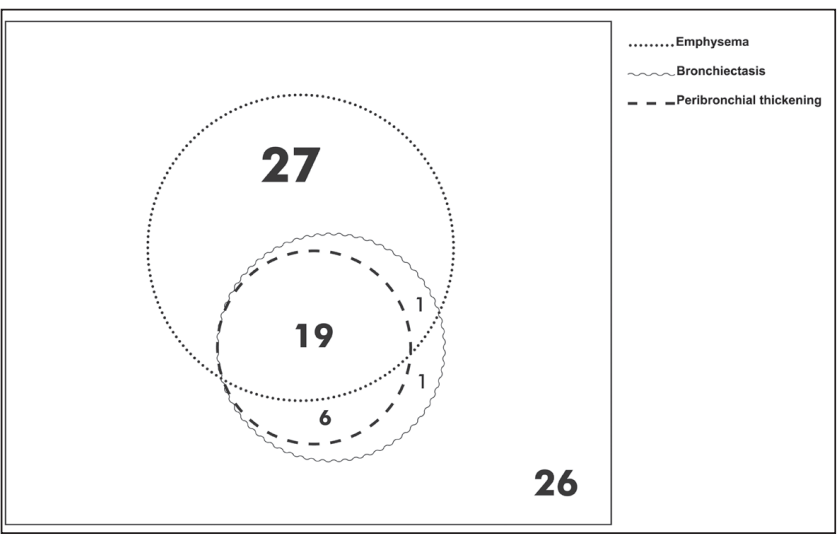

Figure 3) Proportional Venn diagram representing patients with emphysema, bronchiectasis and peribronchial thickening on computed tomography scanning

between the $\mathrm{E}+\mathrm{B} / \mathrm{PBT}$ and the $\mathrm{B} / \mathrm{PBT}$ patients did not demonstrate a significant difference, while CRP values and number of exacerbations were only apparently higher in the E+B/PBT group. Bonferroni correction was used to evaluate the significance levels of type-I error for pairwise comparisons; values $<0.0166$ were considered to be statistically significant (Table 5).

The median score for all patients according to the Bhalla system was 2 (range 0 to 17). Examining the patients according to Global initiative for Obstructive Lung Disease (GOLD) stage, the median HRCT scores and range were distributed as follows, proceeding from mild (I) to very severe (IV): 0 (0 to 2); 1 (0 to 7 ); 7 (1 to 17 ); 6 (2 to 7) (Figure 4). An inverse correlation was found between the total HRCT score and FVC $(r=-0.561 ; \mathrm{P}<0.001), \mathrm{FEV}_{1} \quad(\mathrm{r}=-0.710$; $\mathrm{P}<0.001)$ and $\mathrm{FEV}_{1} / \mathrm{FVC}(\mathrm{r}=-0.623 ; \mathrm{P}<0.001)$, while the correlation 


\begin{tabular}{|c|c|c|c|}
\hline Characteristic & None $(n=26)$ & B/PBT/E (n=54) & $\mathbf{P}$ \\
\hline Age, years & $68 \pm 7.3$ & $68 \pm 8$ & NS \\
\hline Sputum/day, mL, n (\%) & & & NS \\
\hline$<5$ & $11(42.3)$ & $23(42.6)$ & NS \\
\hline $5-25$ & $9(34.6)$ & $20(37.0)$ & NS \\
\hline$>25$ & $6(23.1)$ & $11(20.4)$ & NS \\
\hline Smoking, pack-years & $32.5 \pm 18.0$ & $34.0 \pm 12.4$ & NS \\
\hline Duration of COPD symptoms & $12.0 \pm 7.4$ & $11.4 \pm 5.9$ & NS \\
\hline Exacerbations in previous year & $0.3 \pm 0.5$ & $2.2 \pm 1.6$ & $<0.001$ \\
\hline FVC, \% predicted & $91.0 \pm 12.4$ & $74.2 \pm 15.7$ & $<0.001$ \\
\hline $\mathrm{FEV}_{1}, \%$ predicted & $74.1 \pm 11.8$ & $48.9 \pm 16.8$ & $<0.001$ \\
\hline $\mathrm{FEV}_{1} / \mathrm{FVC}$ & $64.8 \pm 6.2$ & $52.3 \pm 11.4$ & $<0.001$ \\
\hline C-reactive protein, $\mathrm{mg} / \mathrm{L}$ & $3.5 \pm 0.7$ & $9.4 \pm 7.2$ & $<0.001$ \\
\hline $\mathrm{ESR}, \mathrm{mm} / \mathrm{h}$ & $17.5 \pm 13.7$ & $29.2 \pm 20.5$ & 0.01 \\
\hline Albumin, $g / L$ & $40 \pm 5.0$ & $39 \pm 4.0$ & NS \\
\hline
\end{tabular}

Data presented as mean $\pm S D$ unless otherwise indicated. COPD Chronic obstructive pulmonary disease; ESR Erythrocyte sedimentation rate; FEV 1 Forced expiratory volume in $1 \mathrm{~s}$; FVC Forced vital capacity

\section{TABLE 4}

Clinical, spirometric and laboratory comparisons among patients with E only, B/PBT only and E+B/PBT

\begin{tabular}{lcccc}
\hline & $\begin{array}{c}\text { E only } \\
(\mathbf{n}=\mathbf{2 7})\end{array}$ & $\begin{array}{c}\text { B/PBT only } \\
(\mathbf{n}=\mathbf{7})\end{array}$ & $\begin{array}{c}\mathbf{E}+\mathrm{B} / \mathrm{PBT} \\
(\mathbf{n}=\mathbf{2 0})\end{array}$ & $\mathbf{P}$ \\
\hline Age, years & $67 \pm 9$ & $68 \pm 5$ & $68 \pm 8$ & $\mathrm{NS}$ \\
Smoking, pack-years & $33.8 \pm 13.7$ & $35 \pm 10.0$ & $33.9 \pm 12.0$ & $\mathrm{NS}$ \\
Duration of COPD & $11.9 \pm 5.5$ & $10.7 \pm 5.5$ & $10.1 \pm 6.6$ & $\mathrm{NS}$ \\
$\quad$ symptoms, years & & & & \\
Exacerbations in & $1.1 \pm 1.0$ & $2.8 \pm 0.2$ & $3.6 \pm 1.2$ & $<0.001$ \\
$\quad$ previous year & & & & \\
FVC, \% predicted & $79.0 \pm 16.1$ & $70.1 \pm 10.5$ & $67.9 \pm 15.1$ & 0.03 \\
FEV,$\%$ predicted & $56.6 \pm 16.2$ & $42.0 \pm 12.7$ & $38.8 \pm 12.2$ & 0.002 \\
FEV 1 /FVC & $56.3 \pm 10.6$ & $49.3 \pm 9.4$ & $47.7 \pm 11.4$ & 0.02 \\
CRP, mg/mL & $5.4 \pm 4.0$ & $9.8 \pm 2.9$ & $14.6 \pm 8.1$ & $<0.001$ \\
ESR, mm/h & $25.6 \pm 23.0$ & $30.6 \pm 16.0$ & $34.1 \pm 18.2$ & $\mathrm{NS}$ \\
Albumin, g/L & $39 \pm 4.0$ & $38 \pm 5.0$ & $40 \pm 4.0$ & $\mathrm{NS}$ \\
\hline
\end{tabular}

Data presented as mean $\pm S D$ unless otherwise indicated. B Bronchiectasis; COPD Chronic obstructive pulmonary disease; CRP C-reactive protein; $E$ Emphysema; ESR Erythrocyte sedimentation rate; FEV 1 Forced expiratory volume in 1 s; FVC Forced vital capacity; NS Not statistically significant; PBT Peribronchial thickening

was positive for CRP level $(\mathrm{r}=0.785 ; \mathrm{P}<0.001)$, ESR $(\mathrm{r}=0.322 ; \mathrm{P}=0.006)$ and the number of exacerbations $(r=0.814 ; \mathrm{P}<0.001)$. Significant correlations were also found between certain structural parameters used in scoring, and between spirometry measurements and CRP, ESR and exacerbation counts (Table 6).

\section{Interobserver agreement}

Interobserver agreement for HRCT scores was characterized as fair to substantial, yielding the following coefficients and significance levels: agreement for overall score $\kappa=0.68, \mathrm{P}<0.001$; severity of $\mathrm{B} \kappa=0.62$, $\mathrm{P}<0.001$; $\mathrm{PBT} \kappa=0.28, \mathrm{P}=0.002$; extent of $\mathrm{B} \kappa=0.72, \mathrm{P}<0.001$; extent of mucus plugging $\kappa=0.32, \mathrm{P}<0.001$; generations of bronchial divisions involved $\kappa=0.62, \mathrm{P}<0.001$; number of bullae $\kappa=0.76, \mathrm{P}<0.001$; emphysema $\kappa=0.47, \mathrm{P}=0.001$; collapse/consolidation $\kappa=0.44, \mathrm{P}=0.003$; and mosaic perfusion $\kappa=0.80, \mathrm{P}<0.001$.

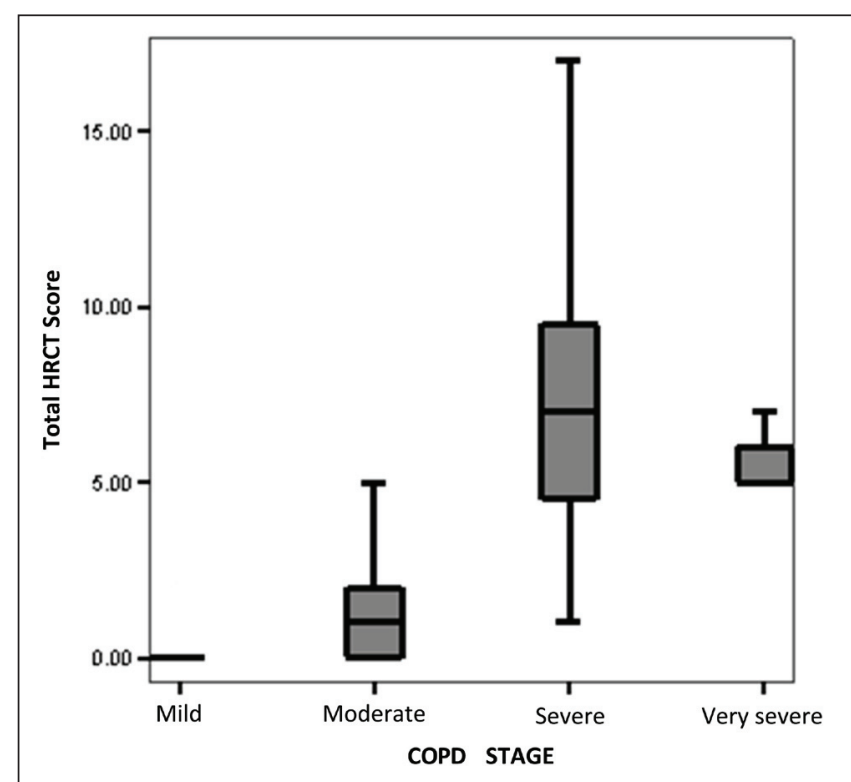

Figure 4) The median total high-resolution computed tomography (HRCT) scores according to the Global initiative for Obstructive Lung Disease stages. COPD Chronic obstructive pulmonary diease

\section{DISCUSSION}

In the present study, which included 80 patients at all stages of COPD from mild to very severe, 26 had no morphological abnormality while 54 had at least one. Patients with no morphological abnormality had mild to moderate COPD according to GOLD stage, and were similar in age, smoking history and duration of COPD symptoms to patients who had HRCT findings. In the latter group, spirometric measurements were worse, and number of exacerbations, CRP and ESR values were higher than those in the first group. These results showed that HRCT examinations may provide direct measurements of pulmonary pathologies and have good correlation with some commonly used clinical measurements in COPD patients, similar to that reported in a limited number of studies in the literature (12). Providing direct measurements of pulmonary pathologies via HRCT may contribute to improved disease management in COPD patients.

We divided patients with HRCT findings into one of three groups: E only, E+B/PBT and B/PBT only; comparison of the latter two groups with the former showed significantly worse or lower values for $\mathrm{FEV}_{1}$ and the $\mathrm{FEV}_{1} / \mathrm{FVC}$ ratio. This same comparison also revealed significantly higher CRP levels and one-year exacerbation counts in the $\mathrm{E}+\mathrm{B} / \mathrm{PBT}$ and $\mathrm{B} / \mathrm{PBT}$ groups compared with the $\mathrm{E}$ only group. The number of exacerbations during the past year and the CRP levels of patients with B/PBT in their HRCT were approximately two- to threefold higher than those with $\mathrm{E}$ only. A comparison of B/PBT with or without $\mathrm{E}$ did not reveal any significant differences. This result led us to believe that the presence of B/PBT in COPD patients was associated with a more severe clinical course.

Bronchiectasis and COPD have many common clinical and pathological characteristics (13-16). Publications reporting that an important proportion of COPD patients also have bronchiectasis have been increasing in recent years. Patel et al (17) determined that $50 \%$ of the patients in their study had bronchiectasis. Bronchial inflammation and the chronic presence of potentially pathogenic microorganisms (PPM) are more frequent and more extensive in patients with COPD and bronchiectasis, and their infectious exacerbations last longer. Another recent study (18) found a $57.6 \%$ frequency of bronchiectasis in COPD patients. Bronchiectasis in these patients was independently associated with severe airflow obstruction, PPM cultured in the sputum and $\geq 1$ exacerbations with hospitalization in the past year. In our study, cases with concomitant bronchiectasis comprised $33.8 \%$ of the patient population. 
TABLE 5

Pairwise comparisons of the patient groups regarding FVC, FEV , FEV $_{1}$ /FVC, CRP, ESR and number of exacerbations

\begin{tabular}{|c|c|c|c|c|c|c|c|}
\hline \multicolumn{2}{|c|}{ Pairwise comparison groups } & \multicolumn{6}{|c|}{$\mathrm{P}^{*}$} \\
\hline Group 1 & Group 2 & FVC & $\mathrm{FEV}_{1}$ & $\mathrm{FEV}_{1} / \mathrm{FVC}$ & CRP & ESR & Exacerbations \\
\hline E alone & B/PBT alone & 0.02 & $0.01^{*}$ & NS & $0.01^{*}$ & NS & $<0.001^{*}$ \\
\hline
\end{tabular}

*Bonferroni correction was used to evaluate the significance levels of type 1 error for pairwise comparisons and values <0.0166 were considered to be statistically significant. B Bronchiectasis; CRP C-reactive protein; E Emphysema; ESR Erythrocyte sedimentation rate; FEV 1 Forced expiratory volume in 1 s; FVC Forced vital capacity; PBT Peribronchial thickening

TABLE 6

Univariate (Spearman's rho) correlations between structural features on HRCT and FVC, FEV 1 , FEV 1 /FVC ratio, CRP level, ESR and number of exacerbations in previous year

\begin{tabular}{|c|c|c|c|c|c|c|c|c|}
\hline \multirow[b]{2}{*}{ HRCT feature } & \multicolumn{2}{|c|}{$\mathrm{FEV}_{1}$} & \multicolumn{2}{|c|}{ CRP } & \multicolumn{2}{|c|}{ ESR } & \multicolumn{2}{|c|}{ Exacerbations } \\
\hline & $r$ & $\mathbf{P}$ & $r$ & $\mathbf{P}$ & $r$ & $\mathbf{P}$ & $r$ & $\mathbf{P}$ \\
\hline Severity of bronchiectasis & -0.57 & $<0.001$ & 0.69 & $<0.001$ & 0.36 & 0.002 & 0.73 & $<0.001$ \\
\hline Peribronchial thickening & -0.59 & $<0.001$ & 0.76 & $<0.001$ & 0.36 & 0.002 & 0.75 & $<0.001$ \\
\hline Extent of bronchiectasis & -0.59 & $<0.001$ & 0.72 & $<0.001$ & 0.32 & 0.006 & 0.75 & $<0.001$ \\
\hline Extent of mucus plugging & -0.26 & $0.02^{*}$ & 0.38 & 0.001 & 0.09 & 0.46 & 0.37 & 0.001 \\
\hline Generations of bronchial divisions & -0.55 & $<0.001$ & 0.70 & $<0.001$ & 0.37 & 0.001 & 0.73 & $<0.001$ \\
\hline Number of bullae & -0.37 & 0.001 & 0.51 & $<0.001$ & 0.15 & 0.20 & 0.47 & $<0.001$ \\
\hline Emphysema & -0.50 & $<0.001$ & 0.39 & $<0.001$ & 0.18 & 0.13 & 0.46 & $<0.001$ \\
\hline Collapse/consolidation & -0.01 & 0.93 & 0.20 & 0.08 & 0.05 & 0.67 & 0.10 & 0.36 \\
\hline Mosaicperfusion & -0.07 & 0.53 & 0.27 & $0.02^{\star}$ & 0.21 & 0.08 & 0.20 & 0.09 \\
\hline Total HRCT score & -0.71 & $<0.001$ & 0.79 & $<0.001$ & 0.32 & 0.006 & 0.81 & $<0.001$ \\
\hline
\end{tabular}

CRP C-reactive protein; ESR Erythrocyte sedimentation rate; FEV 1 Forced expiratory volume in 1 s; FVC Forced vital capacity; HRCT High-resolution computed tomography

We believe that the higher proportion of bronchiectasis in these two studies $(17,18)$ may be due to the fact that those patient populations consisted of cases with moderate to severe COPD. In our study, however, $17.5 \%$ of the patients had mild disease and, when these were excluded, the bronchiectasis rate rose to $40 \%$. The scores for the extent and severity of bronchiectasis in our patients were significantly correlated with $\mathrm{FEV}_{1}$, CRP and ESR values, as well as the number of exacerbations.

Current guidelines continue to consider spirometric measurements, chiefly $\mathrm{FEV}_{1}$, to be most important in diagnosing COPD and determining its severity. While they are generally useful, these functional measurements are not, by themselves, sufficient to characterize the heterogeneous pathological processes in COPD. Quantitative evaluations of CT imaging results have been shown to be associated with airway function measurements $(19,20)$, main COPD outcome parameters (20-22) and systemic inflammatory mediator levels (23). The use of CT imaging as an index for respiratory tract disease remains to be validated $(24,25)$. Our study confirmed the presence of significant correlations calculated using Spearman's rank correlation between HRCT scores and the values of $\mathrm{FEV}_{1}$ and $\mathrm{CRP}$ and the number of exacerbations. It was interesting to note that while the correlations between HRCT scores or spirometric measurements and the exacerbation count were comparable, the correlation between HRCT score and CRP levels was stronger than between HRCT score and spirometry ( $r=0.785$ and $\mathrm{r}=0.596$, respectively).

CRP is a useful marker of systemic inflammation. It is easily measured and widely used in clinical practice. CRP levels have been shown to be elevated in patients with stable COPD (26). Some studies have reported an inverse relationship between CRP levels and $\mathrm{FEV}_{1}$; several reports also suggest that CRP may be a strong long-term outcome predictor for COPD/airway obstruction (27-29). Our study found a significant correlation between HRCT score and CRP levels; CRP levels were also higher in $\mathrm{B} / \mathrm{PBT}$ patients compared with the $\mathrm{E}$ only group. A direct correlation between bronchial microbial colonization and CRP levels has been reported (30). The high CRP level in our patients with B is likely related to increased bronchial microbial colonization. However, the absence of PPM culture was a limitation of our study.
In a study investigating the relationship among emphysema frequency, severity of COPD and CRP levels in 651 male patients, Omori et al (31) showed that the severity of COPD was variable across patients with comparable degrees of emphysema. CRP levels were not higher in patients with mild or moderate emphysema compared with those with no emphysema in this study. Although substantially elevated CRP levels were detected in patients with severe emphysema, this group only comprised two patients. CRP values were higher in patients with emphysema in our study compared with those without this condition $(5.4 \mathrm{mg} / \mathrm{L}$ versus $3.5 \mathrm{mg} / \mathrm{L})$; E scores were also significantly correlated with both $\mathrm{FEV}_{1}$ and CRP measurements. In our opinion, the differences between our study and the study by Omori et al (31) were due to differences in patient populations. While the COPD severity grade of our patients ranged from mild to very severe, participants in the study by Omori et al (31) were relatively healthier.

Morphological changes observed using HRCT may contribute substantially to the management of COPD. Kitaguchi et al (6) reported significant linkage between the presence of bronchial wall thickening, sputum eosinophilia and response to corticosteroid therapy. MartinezGarcia et al (18) indicated that bronchiectasis is related to pathological bacterial colonization, mainly by Pseudomonas species, and that this may be a predictor of exacerbations. This prompts us to recommend that studies evaluating the efficacy of bronchiectasis treatments, such as inhaled antibiotics, macrolides and airway clearance modalities, should also be performed in patients with overlapping COPD and B (32). Consistent with our study, it has been shown that CT-detected increases in E and airway wall thickness are associated with exacerbation frequency, suggesting that HRCT may help in the identification of patient subgroups with exacerbations for targeted research or phenotype-specific therapy (33). Because CT is widely used in both daily practice and lung cancer screening trials, it may become a useful tool for the detection of new COPD, and also for identification of subclinical COPD cases with normal pulmonary function tests or in which pulmonary function testing is not routinely performed (12). Additionally, HRCT may also help in the selection of patients for lung volume reduction applications and evaluation of response to alpha-1 antitrypsin augmentation therapy (34-36). 
HRCT phenotyping is not widely used in routine practice despite its substantial benefits. Radiation dose and cost effectiveness may be important issues limiting its routine use. However, currently, quantitative CT is possible with low-dose protocols and, even when individuals are exposed multiple times, the cumulative radiation dose remains relatively low (12).

In our study, interobserver agreement ranged from fair to substantial. Although relatively low, agreement values (ie, $\kappa$ ) in our study were consistent with those reported in previous studies $(10,37)$. Recently, however, quantitative automated evaluation of CT measures, especially E quantification, appeared to be superior to visual evaluation by human observers (37). Therefore, quantitative analysis of some of the morphological changes on HRCT in the present study may have improved the levels of interobserver agreement.

\section{CONCLUSION}

Our study exposed the intimate relationship between phenotypes characterized by HRCT and the scoring for morphological abnormalities on one hand and the clinical and functional parameters and inflammatory markers on the other. The inclusion of HRCT among routine examinations for COPD may provide significant benefits in the management of patients with COPD. However, additional studies are needed to recommend HRCT phenotyping of all patients with COPD.

ACKNOWLEDGEMENTS: BT designed the study, supervised the conduct of the study, clinically assessed study patients and drafted the manuscript. ASK and SO analyzed HRCT scans. FK and MS led patient recruitment, conducted patient assessment, and provided guidance and assistance with study design. All authors contributed to and reviewed the manuscript. The authors thank to Nart Bedin Atalay PhD and Guler Yavas MD for advising on statistical procedures.

\section{REFERENCES}

1. Calverley PM, Walker P. Chronic obstructive pulmonary disease. Lancet 2003;362:1053-61.

2. Ferrer M, Alonso J, Morera J, et al. Chronic obstructive pulmonary disease stage and health-related quality of life. The Quality of Life of Chronic Obstructive Pulmonary Disease Study Group. Ann Intern Med 1997;127:1072-9.

3. Halbert RJ, Natoli JL, Gano A, Badamgarav E, Buist AS, Mannino DM. Global burden of COPD: A systematic review and meta-analysis. Eur Respir J 2006;28:523-32.

4. Han MK, Agusti A, Calverley PM, et al. Chronic obstructive pulmonary disease phenotypes: The future of COPD. Am J Respir Crit Care Med 2010;182:598-604.

5. Copley SJ, Wells AU, Muller NL, et al. Thin-section CT in obstructive pulmonary disease: Discriminatory value. Radiology 2002;223:812-9.

6. Kitaguchi Y, Fujimoto K, Kubo K, Honda T. Characteristics of COPD phenotypes classified according to the findings of HRCT. Respir Med 2006;100:1742-52.

7. Bafadhel M, Umar I, Gupta S, et al. The role of CT scanning in multidimensional phenotyping of COPD. Chest 2011;140:634-42.

8. Bhalla M, Turcios N, Aponte V, et al. Cystic fibrosis: Scoring system with thin-section CT. Radiology 1991;179:783-8.

9. Demirkazik FB, Ariyurek OM, Ozcelik U, Gocmen A, Hassanabad HK, Kiper N. High resolution CT in children with cystic fibrosis: Correlation with pulmonary functions and radiographic scores. Eur J Radiol 2001;37:54-9.

10. Judge EP, Dodd JD, Masterson JB, Gallagher CG. Pulmonary abnormalities on high-resolution CT demonstrate more rapid decline than $\mathrm{FEV}_{1}$ in adults with cystic fibrosis. Chest 2006;130:1424-32.

11. Global initiative for Chronic Obstructive Lung Disease. Global Strategy for the diagnosis, Mangement, and Prevention of Chronic Obstructive Pulmonary Disease. <wwwgoldcopdcom/2011> (Accessed November 30, 2012).

12. Mets OM, de Jong PA, van Ginneken B, Gietema HA, Lammers JW. Quantitative computed tomography in COPD: Possibilities and limitations. Lung 2012;190:133-45.

13. Stockley RA. Neutrophils and the pathogenesis of COPD. Chest 2002;121(5 Suppl):151S-5S.

14. Fuschillo S, De Felice A, Balzano G. Mucosal inflammation in idiopathic bronchiectasis: Cellular and molecular mechanisms. Eur Respir J 2008;31:396-406.
15. Chronic obstructive pulmonary disease. National clinical guideline on management of chronic obstructive pulmonary disease in adults in primary and secondary care. Thorax 2004;59(Suppl 1):1-232.

16. Martinez-Garcia MA, Soler-Cataluna JJ, Perpina-Tordera M, Roman-Sanchez P, Soriano J. Factors associated with lung function decline in adult patients with stable non-cystic fibrosis bronchiectasis. Chest 2007;132:1565-72.

17. Patel IS, Vlahos I, Wilkinson TM, et al. Bronchiectasis, exacerbation indices, and inflammation in chronic obstructive pulmonary disease. Am J Respir Crit Care Med 2004;170:400-7.

18. Martinez-Garcia MA, Soler-Cataluna JJ, Donat Sanz Y, et al. Factors associated with bronchiectasis in patients with COPD. Chest 2011;140:1130-7.

19. Yuan R, Hogg JC, Pare PD, et al. Prediction of the rate of decline in $\mathrm{FEV}(1)$ in smokers using quantitative computed tomography. Thorax 2009;64:944-9.

20. O'Donnell RA, Peebles C, Ward JA, et al. Relationship between peripheral airway dysfunction, airway obstruction, and neutrophilic inflammation in COPD. Thorax 2004;59:837-42.

21. Han MK, Bartholmai B, Liu LX, et al. Clinical significance of radiologic characterizations in COPD. COPD 2009;6:459-67.

22. Ogawa E, Nakano Y, Ohara T, et al. Body mass index in male patients with COPD: Correlation with low attenuation areas on CT. Thorax 2009;64:20-5.

23. Bon JM, Leader JK, Weissfeld JL, et al. The influence of radiographic phenotype and smoking status on peripheral blood biomarker patterns in chronic obstructive pulmonary disease. PLoS One 2009;4:e6865.

24. Coxson HO. Quantitative computed tomography assessment of airway wall dimensions: current status and potential applications for phenotyping chronic obstructive pulmonary disease. Proc Am Thorac Soc 2008;5:940-5.

25. Coxson HO, Lam S. Quantitative assessment of the airway wall using computed tomography and optical coherence tomography. Proc Am Thorac Soc 2009;6:439-43.

26. Pinto-Plata VM, Mullerova H, Toso JF, et al. C-reactive protein in patients with COPD, control smokers and non-smokers. Thorax 2006;61:23-8.

27. Broekhuizen R, Wouters EF, Creutzberg EC, Schols AM. Raised CRP levels mark metabolic and functional impairment in advanced COPD. Thorax 2006;61:17-22.

28. Man SF, Connett JE, Anthonisen NR, Wise RA, Tashkin DP, Sin DD. $\mathrm{C}$-reactive protein and mortality in mild to moderate chronic obstructive pulmonary disease. Thorax 2006;61:849-53.

29. Dahl M, Vestbo J, Lange P, Bojesen SE, Tybjaerg-Hansen A, Nordestgaard BG. C-reactive protein as a predictor of prognosis in chronic obstructive pulmonary disease. Am J Respir Crit Care Med 2007;175:250-5.

30. Marin A, Garcia-Aymerich J, Sauleda J, et al. Effect of bronchial colonisation on airway and systemic inflammation in stable COPD. COPD 2012;9:121-30.

31. Omori H, Tsuji M, Sata K, et al. Correlation of C-reactive protein with disease severity in CT diagnosed emphysema. Respirology 2009;14:551-8.

32. O'Donnell AE. Bronchiectasis in patients with COPD: A distinct COPD phenotype? Chest 2011;140:1107-8.

33. Han MK, Kazerooni EA, Lynch DA, et al. Chronic obstructive pulmonary disease exacerbations in the COPDGene study: Associated radiologic phenotypes. Radiology 2011;261:274-82.

34. Nakano Y, Coxson HO, Bosan S, et al. Core to rind distribution of severe emphysema predicts outcome of lung volume reduction surgery. Am J Respir Crit Care Med 2001;164:2195-9.

35. Flaherty KR, Kazerooni EA, Curtis JL, et al. Short-term and longterm outcomes after bilateral lung volume reduction surgery: Prediction by quantitative CT. Chest 2001;119:1337-46.

36. Stockley RA, Parr DG, Piitulainen E, Stolk J, Stoel BC, Dirksen A. Therapeutic efficacy of alpha-1 antitrypsin augmentation therapy on the loss of lung tissue: An integrated analysis of 2 randomised clinical trials using computed tomography densitometry. Respir Res 2010;11:136.

37. Mets OM, Smit EJ, Mohamed Hoesein FA, et al. Visual versus automated evaluation of chest computed tomography for the presence of chronic obstructive pulmonary disease. PLoS One 2012;7:e42227. 


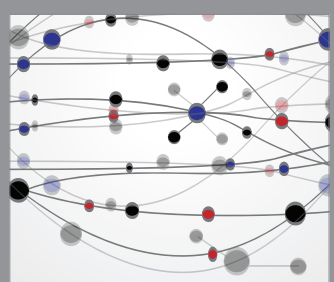

The Scientific World Journal
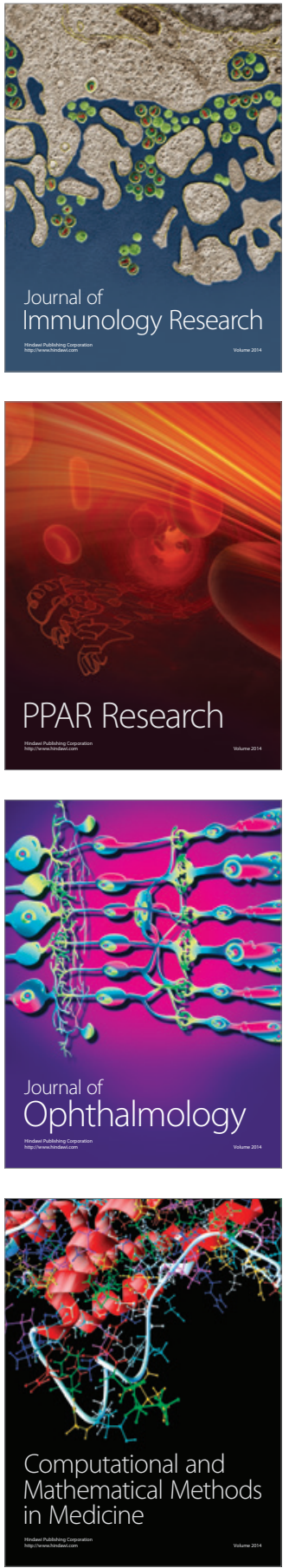

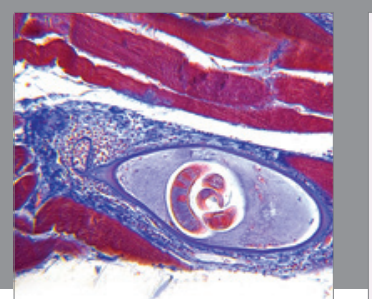

Gastroenterology Research and Practice

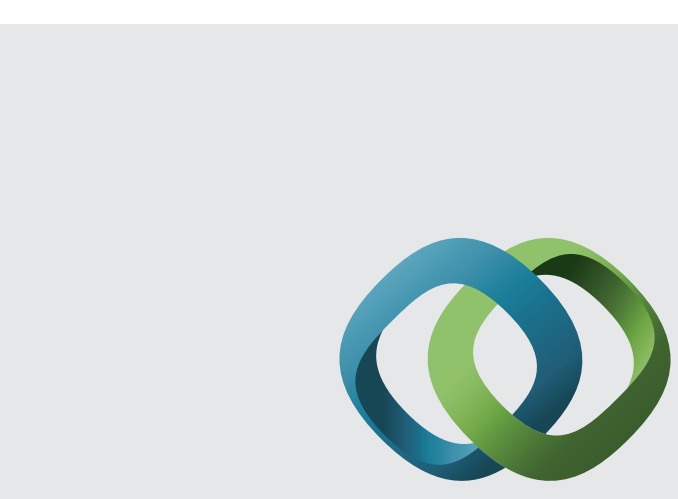

\section{Hindawi}

Submit your manuscripts at

http://www.hindawi.com
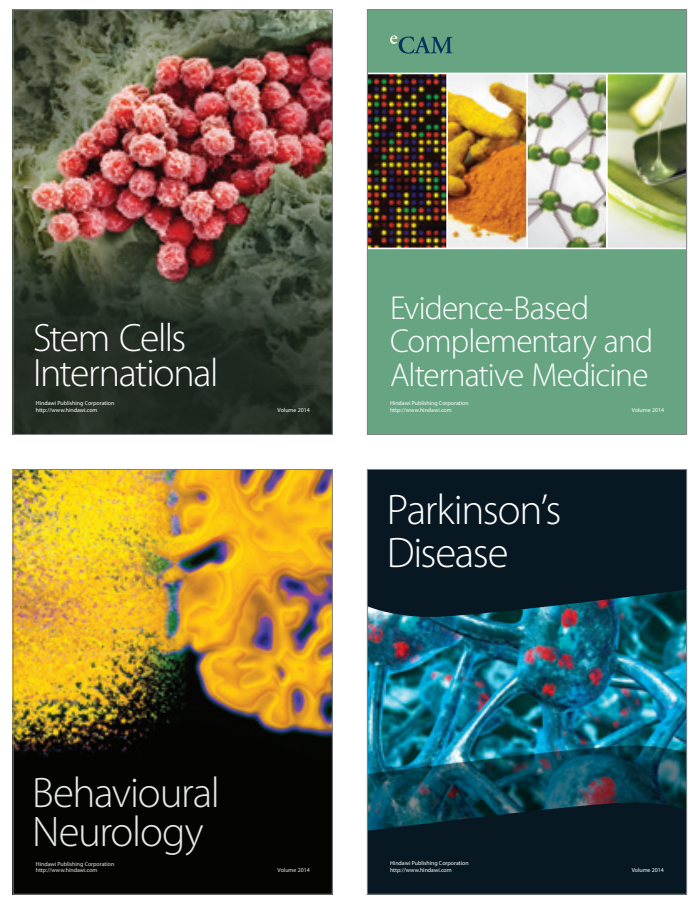
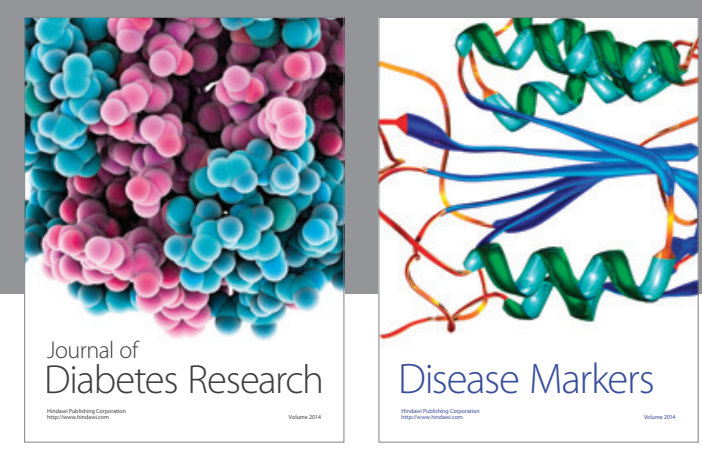

Disease Markers
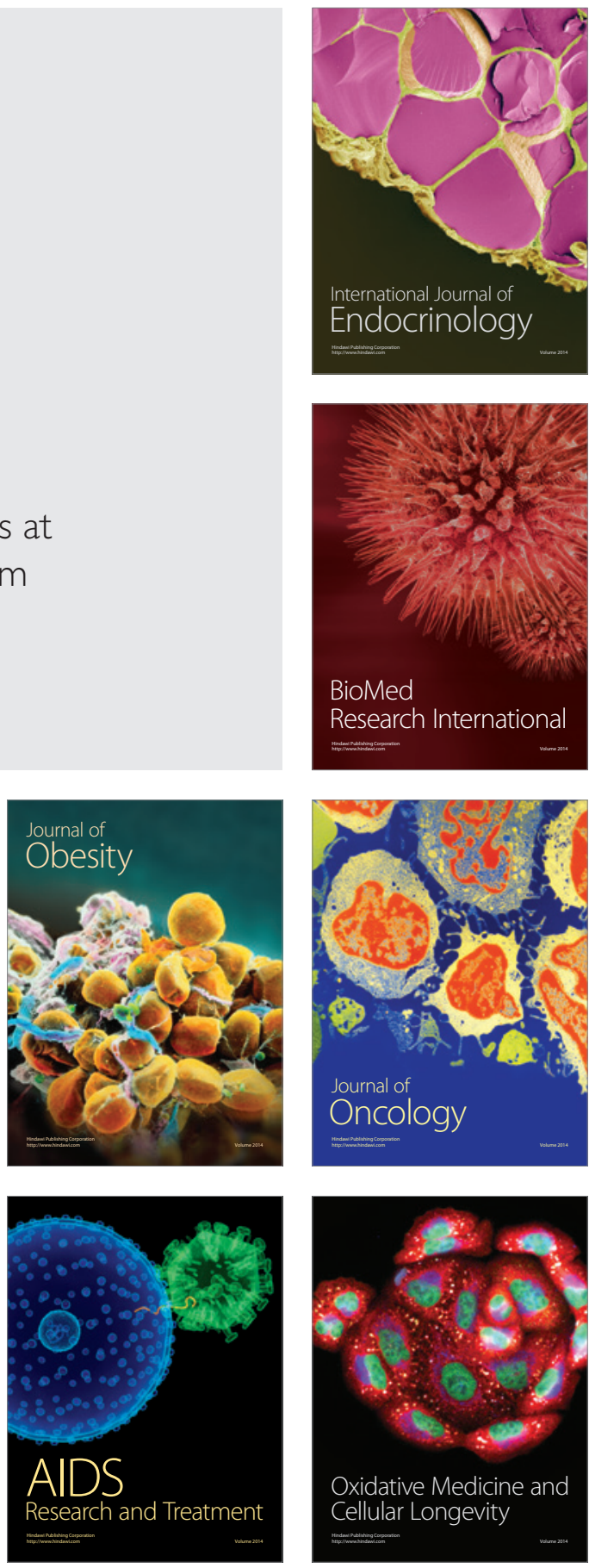